\title{
State-Community System of Care Development: An Exploratory Longitudinal Review
}

\author{
Isaac Karikari, Betty Walton, Christine Bishop, Stephanie Moynihan \& Pinkie Evans
}

\begin{abstract}
The system of care (SOC) philosophy evolved into a framework to support access to effective behavioral health services for children. This study explored the use of the System of Care Implementation Survey (SOCIS) to monitor SOC development during one Midwestern state's federal planning and expansion grants. Utilizing a translational framework, results showed that despite fluctuations in SOC factor implementation over time, state and local SOCs had mid-level development. Further, inferential analysis of select factors indicated that outreach and access to services and the skilled provider network were significantly worse over time. Significant improvement in the treatment quality was documented, but not sustained. Changes for Family Choice and Voice and Collaboration were not statistically significant. Variability in survey participation limited the evaluation. Refinement of evaluation methods is needed to monitor progress and to manage SOC development.
\end{abstract}

This is the author's manuscript of the article published in final edited form as:

Karikari, I., Walton, B., Bishop, C., Moynihan, S., \& Evans, P. (2021). State-Community System of Care Development: An Exploratory Longitudinal Review. The Journal of Behavioral Health Services \& Research, 48(2), 240-258. https://doi.org/10.1007/s11414-020-09702-8 


\section{Introduction}

In response to unmet mental health needs of children and youth, the system of care (SOC) value-based philosophy evolved into a framework to support equitable access to effective services and support, research, and evaluation. ${ }^{1-6}$ Explicit values and principles - family driven and youth guided, culturally competent, and community-based - characterized the SOC framework, prioritizing the needs of children and families. ${ }^{7}$ The SOC principles specified a comprehensive array of services; service coordination; prevention and early intervention; equitable access to services; smooth transitions; individualized service planning; services in the least restrictive environment; family participation in service planning, delivery, and evaluation; and integrated, coordinated services across the child-serving systems. ${ }^{4,5,8}$ The SOC framework has been operationalized through inter-agency and cross-sector collaboration characterized by partnerships with families, cultural and linguistic competency, accountable case managers/coordinators, individualized services, home- and-community-based alternatives, natural supports, evidence-based treatment, comprehensive financing, shared outcomes across systems, and cross-agency management information systems. ${ }^{4,5,8-10}$

The complexities of the SOC framework required multi-level implementation of valuebased principles and processes. ${ }^{5}$ Following 18 years of incremental SOC community-based initiatives, one Midwestern state received Child Mental Health Initiative (CMHI) state-level planning and expansion grants. ${ }^{11}$ This study explored the use of a standardized system of care instrument, the System of Care Implementation Survey (SOCIS), ${ }^{9}$ to assess readiness, to inform planning, and to help monitor state and local SOC development.

The level of development and strength of specific SOC factors provided a good indication of service availability and the likelihood of better behavioral and emotional health 
outcomes and supports for children and their families. ${ }^{9,12,13}$ However, building the infrastructure to support effective services and supports for children and youth with behavioral health needs and their families remained a longstanding challenge..$^{3,14-17}$

Following the operationalization of SOC values and principles through federal policy and funding in the mid to late 1980s and beyond, researchers studied changes in child mental health services. $^{2,9}$ Their findings indicated that philosophical shifts and theoretical advancements in service design impacted policies related to behavioral health and brought about transformations in practice. ${ }^{2,}{ }^{18-22}$ Specific changes included increased emphasis on service integration and interdisciplinary practice, redefined roles of youth and families, and a better understanding of social determinants of service utilization and outcomes. ${ }^{8,19,20,23,24}$ Over twenty years, the service array expanded beyond outpatient, inpatient, and residential services to include communitybased care coordination supported through federal CMHI grants and Medicaid funding, but gaps remained. ${ }^{2,15}$ Recognition of the impact of historical or experienced trauma influenced changes in service design and delivery. ${ }^{25-27}$ While a 2008 state-level SOC study found that most states had made progress, most of the changes though encouraging were "limited in scope and depth." 28 (p. 9)

\section{Complexity and Role of SOC Evaluation}

Challenges of SOC implementation, research, and evaluation have been acknowledged. ${ }^{5}$ Evaluation strategies consider multiple levels with outcome measures related to the aspect of SOC being studied due to the complex framework and implementation processes at multiple and multi-faceted levels (state, tribal or territorial jurisdictions, local system, and the service delivery system). ${ }^{5,29}$ 
Systems at the state, tribal, or territorial level can make changes in policies, financing strategies, workforce development, and other structures and processes to support local systems of care. Ideally, system-level evaluations examine these processes and outputs. ${ }^{5}$ As communities or geographic areas tend to have unique demographic, sociocultural, and economic characteristics, localized assessments of SOC implementation are necessary to understand unique factors affecting child behavioral health systems in different communities. ${ }^{30} \mathrm{SOC}$ development evaluations help identify resources and areas needing improvement to inform policy and practice decisions. ${ }^{1,31}$ Periodic monitoring of SOC development helps manage the conditions necessary to provide effective care coordination and treatment. ${ }^{32,33}$ Although evaluations are critical for continuous quality improvement, ${ }^{9,31}$ most jurisdictions do not have the capacity to monitor SOC development and functioning. ${ }^{2}$

\section{The current study}

This study focused on state SOC implementation and development in one Midwestern state with an incremental history of local SOC development. In October 2013, as a recipient of a state-level CMHI planning grant from the Substance Abuse and Mental Health Services Administration (SAMHSA), the state mental health authority, National Alliance on Mental Illness (NAMI), and the state child welfare agency collaborated to develop a strategic plan to enhance the state level SOC. ${ }^{34,35}$ The state SOC strategic plan was informed by cross-system representation, youth and families with lived experience, community providers and other stakeholders. Soon after, stakeholders completed a readiness self-assessment for SOC development using the SOCIS. ${ }^{11}$ Themes from stakeholder input were matched to mean SOCIS factor ratings from the required readiness assessment that had identified state and local SOC resources and concerns. To improve child mental health services, the theory of change assumed 
that increased funding and technical assistance would develop state-level infrastructure (SOC governance board with youth and family involvement, mental health youth services team, technical assistance to local SOCs, evaluation and quality improvement processes) to improve state-level SOC development and support local SOC implementation. Initial strategic goals for SOC expansion focused on seven categories: collaboration, implementation of SOC values, access to effective services and supports, workforce development, finance, social marketing, and local governance. For each goal, specific activities were planned.

SOC expansion. In 2014, a four-year SOC expansion grant focused on building state infrastructure for youth mental health services. The federal/non-federal budget funded key state staff positions: Principle Investigator (PI), a new Grant Director, a new Cultural and Linguistic Competency Coordinator, and a new SOC Technical Assistance (TA) Coordinator for local SOCs. Grant related contracts included SOC TA to the state youth services and grant implementation team; a youth consultant with lived experience; supported family and youth involvement; evaluation services and social marketing consultation. An annual, statewide SOC conference was sponsored through 2018. As local SOC development is related to access to effective wraparound and behavioral health services, the plan supported both state and local SOC development. ${ }^{11,12,33}$

Grant activities. The state grant team received technical assistance through the Technical Assistance Network for Children's Behavioral Health (TA Network) and an external contractor regarding strategic planning, developing and implementation a cultural competency plan, and family and youth involvement. The state grant team provided TA to the local SOCs through onsite consultation visits from the new TA coordinator, monthly conference calls, consultation 
from the external TA consultant, the new SOC Director, and on-site training/consultation by the new Cultural and Linguistic Competency Coordinator.

Collaboration and Governance-Management Transitions. Evolving from an advisory board to support statewide implementation of high fidelity wraparound care coordination, a statelevel governance board was comprised of state organizations, local SOC representatives, advocates, one-third youth and families, and other stakeholders such as YMCA, housing authority, and local government. The state National Alliance on Mental Illness (NAMI) director facilitated meetings in collaboration with the grant PI. Concurrently, a new cross-system commission, established by 2013 legislation, had just begun to study issues related to vulnerable children to promote data sharing and best practices, and to make recommendations to legislation. During the grant, an interagency collaborative was redesigned to engage decision makers from child service agencies and the commission's director. The SOC PI had leadership roles in each body. Toward the end of the SOC grant, governance and management were restructured to be the role of state agencies and the grant's board evolved to an advisory board with diverse representatives of families and youth, advocates, community systems of care, child behavioral health providers, state agencies (education, child welfare, health, Medicaid, office of minority health), and academia.

During the grant, SOC Board subcommittees included a youth and family subcommittee that helped develop and recommend child mental health policies to the board for consideration and approval. Training, TA, and grant funding supported the development and sustainability of the subcommittee. In the last grant year, families with involvement in the state SOC board began helping local SOCs increase youth and family involvement. Other subcommittees were 
workforce development, cultural and linguistic competency, evaluation, and local SOC coordinators.

Two experienced local SOC Coordinators assumed leadership for monthly calls, quarterly SOC in-person training/meetings, and worked closely with the state team. During the grant, the state supported funding of 18 local SOCs through a designated state child mental health fund. In fall 2017, the TA team assessed the knowledge and skills of local coordinators. Although they shared a common understanding of SOC, many lacked needed skills. Subsequent TA focused on skill development. Following the grant, financial support for 17 local SOCs continued with TA provided to 61 local coordinators representing 83 of the state's 92 counties.

SOC activities and development were documented through a qualitative study, which ran in two phases during the implementation grant with key informant interviews, document reviews, and surveys. ${ }^{36,37}$ Progress toward the goal of expanding family and youth involvement at the state level was recognized. The state advisory board cultivated leaders and champions for the SOC approach and monitored emerging policies and protocols. Cultural and linguistic training, technical assistance, and awareness was integrated into state SOC strategies and activities.

Services. Although no expansion grant funds paid for services, the use of evidenceinformed and promising practices expanded. For example, in State Fiscal Year 2014 (SFY14) and SFY18, 3, 380 and 8,247 youth, respectively, participated in Cognitive Behavioral Therapy (CBT); 1,736 and 8,557 youth, respectively, participated in Trauma Focused CBT; and 410 and 2,691 youth, respectively, participated in Functional Family Therapy. Functional outcomes for youth participating in evidence-based practices and were consistently better than outcomes for youth receiving usual services, as measured by the Child and Adolescent Needs and Strengths $(\mathrm{CANS})^{38}$. 
Developing statewide access to high-fidelity wraparound had long been a strategy. Building upon the development of wraparound services through a 2008-2012 Medicaid demonstration grant for youth with complex mental health needs,$^{39}$ the population of concern for this grant was children (ages 6 to 17) who were eligible for a new 1915i Medicaid program in counties beginning the program after April 1, 2015. ${ }^{11}$ By March 2015, the new Medicaid wraparound program was available in 32 of 92 counties. By December 2017, children from 72 counties had participated in the program with expansion to children in nine more counties by the end of the grant in September 2018.

State funding supported training and TA from the University of Maryland's School of Social Work and the Wraparound Evaluation and Research Team. Five state-level coaches were employed to support and manage quality care coordination services statewide. Dedicated state funding to the state child welfare system supported similar care coordination services for children not eligible for Medicaid. Training and certification of wraparound facilitators and supervisors for Medicaid and state funded care coordination was provided by state coaches.

Evaluation. An evaluation committee worked closely with the grant implementation team and governance board, collaborating with local SOCs, youth and families, and the cultural competency committee. Periodic in-person meetings were webcasted to encourage participation in evaluation planning, reviewing findings, and discussing implications. In addition to collecting grant required data, administrative data was utilized to study service utilization, identifying disproportionate access to services and monitoring outcomes by age, gender, race, ethnicity, and geography. As part of the grant's local SOC evaluation, the SOCIS was administered three times to support planning and to monitor progress in state and local SOC development. 
Questions. Related evaluation questions included: What were the initial levels of state and local SOC development during the planning grant? In what areas was progress made? What challenges continued? Were observed changes over time significant and meaningful?

\section{Methods}

\section{Sample}

The study's convenience sample was composed of respondents from state agencies, local counties, and families. Respondents included mental health (MH) service providers; youth, families and advocates (YF); child service organizations (CSO) (e.g., child welfare, juvenile justice, health, residential), education (ED), and other community partners (OCP). Across the

years examined, at state or county levels, respondent types and number of related respondents varied. In the 2014 readiness survey, respondents were primarily from MH (37.3\%) and CSO (30.6\%), followed by ED (14.4\%), OCP (8.9\%), and YF (8.4\%). Over time, fewer MH and CSO respondents and more OCP respondents completed the SOCIS.

Overall, 1,512 respondents from 89 counties participated in the study. However, the number of counties represented in the study varied across the periods examined: 2014 (76 counties), 2016 (67 counties), and 2018 (55 counties).The number of respondents also varied at state and county levels and over time. The percentage of total respondents that rated the statelevel SOC, increased from $12 \%$ in 2014 to $19 \%$ in 2018. The number of respondents from participating counties ranged from one to 39 in 2014, and from one to 23 in 2016 and 2018. Due to the relatively small number of state-level surveys in 2014,2016 , and $2018(75,49$, and 85$)$, respectively, state and local surveys were combined to explore the significance of change in state-community ratings over time. 


\section{Instrument}

This study utilized the SOCIS, Version $2.3 .4,{ }^{3,9,40}$ developed to study CMHI grantees. The SOCIS included 85 items within 15 factors related to system of care implementation and development (Table 1). With each SOCIS factor, a five-point scale was used to rate most questions. Scale rating narrative anchors varied with question's context (e.g., Family Voice and Choice questions, '1-Never/Almost Never, 2-Rarely, 3-Occassionally, 4-Frequently, 5Always/Almost Always'; Transformational Leadership questions, '1-Not at All, 2-Slight Extent, 3-Moderate Extent, 4-Great Extent, 5-Very Great Extent') ${ }^{40}$. A few questions had 'yes' or 'no' options, rated ' 5 ' for yes and ' 1 ' for no. An optional 'Don't Know' rating was not included in analyses as the question rating was missing. Another survey item asked respondents to indicate if they were rating the state or a county SOC. When 'county' was selected, the respondent was asked to specify the county.

\section{(Place Table 1 about here.)}

Validity and reliability. Based upon SOC literature and input from families, youth, and expert opinion, the initial scale was developed, tested in a pilot study to evaluate psychometric properties, and examined through interviews with respondents. ${ }^{9}$ Internal validity of the instrument was tested by interviewing at least four individuals who represented at least different groups within a national sample of counties stratified by population size and poverty level. ${ }^{41}$ All 14 original factors had at least acceptable fit; nine factors had an excellent fit. ${ }^{41}$ The Cronbach's alpha for the overall SOCIS was acceptable, averaging 0.769 across 14 factors. $^{9}$

External validity. External validity was tested by regression analysis to determine if factors were significantly related to communities that had received CMHI funding. ${ }^{33}$ Grantee status was significantly associated with family voice and choice, an implementation plan, 
identification of a local population of concern, endorsement of SOC values and principles, and having a skilled provider network. Comprehensive financial planning and a performance management system were somewhat related to grantee status. Two factors, individualized, comprehensive, culturally competent treatment and outreach and access to care, were not associated with grant funding. ${ }^{41}$

Factorial and concurrent validity. Multilevel confirmatory factor analysis documented the SOCIS factor structure. ${ }^{41}$ Overall, for the first 14 factors, they found evidence of good factorial validity with unidimensionality and significant loadings for all items.

Concurrent validity was confirmed for 11 of the 14 factors when factor latent mean differences were interpreted as real differences between former CMHI grantees and nongrantees. Family voice and choice and implementation plan had equal factorial loadings, but different residual variables between counties. Values and principles had different means, but former grantees had lower ratings on all items within- and between-counties.

Less robust results were found for variability of the factors. Utilizing intraclass correlation, significant between-county variance $(p<.05)$ was found for only six factors: individualized, culturally competent treatment; implementation plan; theory of change; skilled provider network; performance measurement system; and management and governance. The type of respondent completing the survey accounted for a large amount of the variance. Utilizing multilevel confirmatory factor analysis, variability in ratings between counties was related to two dimensions: variability in SOC implementation and variability in respondents' perceptions. Within-county variability could be a limitation for using the survey to measure implementation. ${ }^{41}$ Different patterns of ratings appeared among respondent types. Mental health providers tended to rate SOCIS factors highest; two groups (families and schools) rated factors 
lowest $^{40}$, Specifically, MH providers scored 10 items significantly higher $(p<.05)$ than did families and education. Compared to other child services, mental health providers scored six items significantly higher $(p<.05)$. Education rated four factors significantly higher than families ( $\mathrm{p}<.05$ ), but lower on two. Education was lower than other child services on seven factors (family voice, comprehensive treatment, implementation plan, population of concern, collaboration, finance plan, and provider network), but higher on values. Families rated items four times lower than other respondents. ${ }^{41}$

Regarding explanations for the ratings, consistently higher factor ratings by $\mathrm{MH}$ and child service providers could be related to bias or to increased knowledge. A broader perspective about meeting all students' needs could also be related to lower school ratings. With consistently lower ratings, families with lived experience may not have been as knowledgeable about the service system.

Different perspectives and the small number of respondents in each county contributed to the absence of between county variability. ${ }^{41}$ Respondent type contributed to differences in mean ratings, missing information (incomplete and 'Don't Know' responses), and self-reported knowledge about child mental health services. Mental health respondents had less missing data. SOCIS developers acknowledged that further refinements were needed to address inconsistencies among respondent types.

\section{Procedures}

For this study, in order to make the survey more understandable to families, service providers, and the lay community, with permission from the survey's developers, the evaluation team worked with youth, families, and providers to revise the language of the SOCIS before its use as a readiness assessment in early 2014 . While retaining the meaning of each factor and 
question, the survey's language was simplified. The team used Qualtrics software to create an online version of the SOCIS for data collection. Respondents had the option of completing and mailing in a hard copy of the survey.

Evaluators asked local SOC coordinators to identify and help recruit potential survey respondents with different perspectives (e.g., families/youth, mental health providers, child welfare, juvenile justice, education, advocates) at the local level. The evaluation team sent email invitations to potential key informants with an electronic link to the survey. SOC coordinators assisted in the dissemination of the surveys within their counties or regions of operation. Simultaneously, the state mental health authority and mental health advocacy agencies posted invitations to participate in the study on their websites. Evaluations were also sent invitations to members of the state SOC advisory/governance board and state agencies. During the data collection window, the evaluation team emailed reminders to potential respondents and periodic updates about local response rates to local SOC coordinators, encouraging continued dissemination of the survey. During the 2014 period, the survey remained open for eight weeks; in 2016 the survey was available for nine weeks, and in 2018 for about six weeks. Participation was voluntary; respondent identities were anonymous.

\section{Analyses}

For descriptive and inferential statistical analyses, this study utilized SPSS, version 25.

During the grant, SOCIS factor means were examined to study implementation trends over time. Within each survey period and across time (i.e., 2014, 2016 and 2018), the 15 SOCIS factors were compared at the state, county, and national levels ${ }^{3}$. Kutash and associates' translational guidelines (see below) provided the basis to convert mean results into overall estimates of the degree of SOC development at state and local levels ${ }^{3}$ 
- High level of SOC Implementation = score of ' 3 ' or above on 11 or more of the 15 SOCIS factors.

- Mid-level of SOC Implementation = score of ' 3 ' or above on six to 10 factors.

- Beginning level of SOC Implementation = score of ' 3 ' or above on five or less factors.

To explore the repeated utilization of the SOCIS to monitor progress over time, a oneway between groups multivariate analysis of variance (MANOVA) compared overall SOC development over the three periods, i.e. 2014, 2016, and 2018. Based on the state's SOC strategic plan goals and item-specific response rates, five SOCIS factors were examined: family choice and voice (FCV), individualized culturally competent treatment (ICC), outreach and access to care (OAC), inter-agency and cross-sector collaboration (CC), and skilled provider network (SPN). The five factors were the dependent variables for the one-way MANOVA. The independent variable, SOCIS Year, had three levels: 2014, 2016, and 2018, representing the three time periods. Dependent variables were also considered separately using a Bonferroni-Holm (sequential Bonferroni) procedure to determine statistical significance. Post hoc comparisons were conducted to identify specific differences ${ }^{42}$ between the SOCIS years of implementation.

Missing data. Similar to other studies, some respondents started, but did not complete the survey. Actual reasons were unknown, but post-survey feedback suggested it was due to the length and complexity of the survey. To address missing data, multiple methods were exploredthe SPSS pairwise default, and sensitivity analyses involving only counties represented in all three time points, and multiple imputation. With each of these approaches, the overall trends in SOC development were similar. 
For the sensitivity analysis featuring only data from counties that participated in the study at all three time points, 38 counties were identified. However, all the respondents were providing ratings for the local level which limited the opportunity for state and local level comparisons.

\section{Results}

\section{Descriptive Information}

Respondents. Across time frames, survey respondents' mean age was about 45 years old. Most respondents were Caucasian (90\% to $95 \%$ ) women ( $81 \%$ to $87 \%$ ) reporting 13 to 15 years of active involvement in children's behavioral health services. Table 2 compared the number of state and local survey respondents' roles, agency types, years of experience, age, gender, race, ethnicity, knowledge about local child mental health services, and the extent to which they believed their child mental health services to be a SOC in each time period. The number of respondents for county-level surveys decreased after the planning survey.

(Place Table 2 about here.)

Knowledge. Participants rated their level of knowledge of the local children's mental health system. In $2014,80.7 \%$ of respondents reported being moderately to very knowledgeable. In 2016 and $2018,81.5 \%$ and $72 \%$, respectively, reported being moderately to very knowledgeable. The overall mean rating for participants' knowledge of the local children's mental health system was $4.18(.864)$ in $2014,4.14(.775)$ in 2016 , and $3.92(.918)$ in 2018 . The mean knowledge reported by respondent type varied slightly: 4.14 (.718) for mental health, 3.98 (.850) for youth/ and families, 4.07 (.716) for education, $4.03(.849)$ for other child service agencies, and $3.56(.995)$ for other community partners. 


\section{SOC Development over Time}

Estimating the level of SOC development. Based on Kutash and associates ${ }^{3}$ translational guidelines utilizing the frequency of adequate SOCIS factor means, the state and local (for participating communities) SOCs were at a mid-level of SOC development during initial survey and in subsequent grant years. However, for local SOCs, variability emerged for implementation in specific communities with documented change for many.

State-level SOC factor development. The level of implementation among SOCIS factors differed. At the state level, Skilled Provider Network (SPN) and SOC Values and Principles (VP), respectively, consistently had the lowest and highest levels of implementation in 2014, 2016, and 2018. The number of factors rated as having adequate levels of implementation decreased over time: ten in 2014, eight in 2016, and seven in 2018. Yet, the level of SOC implementation remained within a mid-level range. Ratings for Performance Measurement System (PM) and Provider Accountability (PA) fell below an adequate level in 2016, and General System Performance (GSP) missed the mark in 2018. Other items consistently rated below ' 3 ', requiring attention were: Outreach and Access to Care (OAC), Implementation Plan (IP), Comprehensive Finance Plan (FP), and Population of Concern (POC).

Local-level SOC factor development. Similarly, at the local (county) SOC level, overall SPN and VP were consistently rated as having the lowest and highest levels of implementation, respectively. Regarding other SOC factors, differences from state implementation emerged. Local SOC respondents rated PA as adequate for all periods. OAC, initially rated as being adequately implemented, was later rated as inadequate. Table 3 shows the ratings for all SOCIS factors over time at state and local levels in comparison with national results. ${ }^{3}$

(Insert Table 3 about here.) 


\section{Exploring Change in Specific Factors}

A one-way between groups MANOVA was performed to examine differences in SOC implementation from 2014 to 2018. The five dependent variables were FCV, ICC, OAC, CC, and SPN. The independent variable was SOCIS year with three levels: 2014, 2016, and 2018. There was a statistically significant difference between the three years on the combined dependent variables, $\mathrm{F}(10,1906)=5.40, p=.000$, Wilks Lambda $=.95$, partial eta squared $=$ .03 . Only three percent $(3 \%)$ of the variance in the dependent variables was accounted for by the group factor. The dependent variables were also considered separately using a Bonferroni-Holm (sequential Bonferroni) procedure to determine statistical significance. The adjusted alpha levels, based on the Bonferroni-Holm procedure, were 0.01, 0.013, 0.017, 0.03, and 0.05. The factors reaching statistical significance were $\mathrm{OAC}, \mathrm{F}(2,957)=9.15, p=.000$, partial eta squared $=$ $.019, \mathrm{SPN}, \mathrm{F}(2,957)=6.61, p=.001$, partial eta squared $=.014$, and $\mathrm{ICC}, \mathrm{F}(2,957)=4.17, \mathrm{p}=$ .016, partial eta squared .009. (See Table 4.)

\section{(Insert Table 4 about here.)}

A Tukey post hoc comparison (Table 5) showed that for OAC, there were statistically significant differences between $2014(\mathrm{M}=3.12, \mathrm{SD}=.855)$ and $2016(\mathrm{M}=2.93, \mathrm{SD}=.770),(p$ $<.05), 2014$ and $2018(\mathrm{M}=2.86, \mathrm{SD}=.800),(p<.001)$, but not between 2016 and $2018(p=$ .616). For SPN, there were statistically significant differences between $2014(\mathrm{M}=1.45, \mathrm{SD}=$ $.276)$ and $2016(\mathrm{M}=1.38, \mathrm{SD}=.273),(p<.05), 2014$ and $2018(\mathrm{M}=1.39, \mathrm{SD}=.262),(p<$ .05). However, there were no significant differences between 2016 and $2018(p=.894)$. For ICC, statistically significant differences were detected between $2014(\mathrm{M}=3.89, \mathrm{SD}=.628)$ and 2018 $(\mathrm{M}=3.78, \mathrm{SD}=.567),(p<.05)$, and $2016(\mathrm{M}=3.92, \mathrm{SD}=.532)$ and $2018(p<.05)$, but not between 2014 and $2016(\mathrm{p}=.870)$. 
(Insert Table 5 about here.)

Due to a violation of the homogeneity of variance assumption for ICC and CC, two separate one-way ANOVA tests with a Welch statistic (because of differences in the group sizes) were conducted. For CC, the one-way ANOVA did not yield any statistically significant difference, Welch's F $(2,741.61)=1.46, p>.05$. The result for ICC was statistically significant, Welch's $\mathrm{F}(2,803.18)=4.00, p<.05$. A Games-Howell post hoc comparison showed that there was no statistically significant difference between $2014(\mathrm{M}=3.89, \mathrm{SD}=.627)$ and $2016(\mathrm{M}=$ $3.91, \mathrm{SD}=.547) \mathrm{p}>.05$, and 2014 and $2018(\mathrm{M}=3.80, \mathrm{SD}=.595) p>.05$. However, there was a statistically significant difference between 2016 and 2018, $p<.05$. (See Table 6.)

(Insert Table 6 about here.)

\section{Discussion}

Unlike public health surveys that report the presence or absence of health conditions, the SOCIS focuses on the conditions necessary for children, youth, and families to have access to effective behavioral health services. ${ }^{3}$ This study focused on the utilization of the SOCIS to inform planning and to monitor SOC implementation in a state-community partnership. As a readiness assessment, the SOCIS informed initial strategic planning for a subsequent SOC expansion grant. Over five years, three administrations of the SOCIS reflected the perceived status of factors related to SOC values and principles. ${ }^{9}$ Utilizing a mixture of translational and statistical analyses, researchers explored the utility of repeating the SOCIS to monitor SOC developmental trends.

\section{Translational Analysis}

Following Kutash and associate's translational rating guide ${ }^{3}$, ranges of adequately rated factors were interpreted as at a beginning, mid, or high level of implementation. During the 
grants, the state and, on average, local SOCs functioned within a mid-level range with six to ten factors out of 15 rated as adequate.

Patterns of SOCIS factor ratings in the current study were usually consistent with results from the national study of federally funded SOCs (Table 3$){ }^{3}$ A notable exception was for Interagency and Cross-Sector Collaboration (Collaboration). In contrast to an inadequate SOCIS national mean rating for collaboration ${ }^{3}$, collaboration was rated as adequate at the state and local level SOCs in the 2014 readiness SOCIS as well as in 2016 and 2018. Interestingly, in readiness self-assessments required for CMHI planning grants, collaboration has often been rated as high. ${ }^{30}$ Similar to other readiness survey results, this study's initial results may have reflected the heightened engagement of systems, child service providers, families, youth, and advocates to identify resources and challenges in preparation for an expansion grant. Alternatively, or even complementarily, the state's initial results may also be reflective of its history of incremental local SOC development prior to receiving the CMHI grants from SAMHSA. The adequate ratings reported for 2016 and 2018 may also be indicative of the state's strategic focus on building and strengthening collaboration which remained consistent throughout the grants.

Other studies that have reported improvements in interagency collaboration have also been critiqued for deficits in their operationalization of collaboration with concerns about their limited focus on information exchange, resource sharing, and failure to consider multi-sector involvement in governance, service planning, etc. ${ }^{43}$ In the current study, collaboration encompassed multi-sector and interagency involvement in governance, resource sharing, service planning, staff training, and program evaluation. This view of collaboration is consistent with the national study with which the comparison is made. ${ }^{3}$ 
Initially, as a self-assessment, the SOCIS provided a framework to operationalize SOC implementation, to identify areas of adequate state implementation and to gauge the level of SOC development in specific counties. With a history of SOC development in some communities and the emergence of a state-level Child Mental Health Advisory Board to support and to sustain high quality wraparound services, some components were in place, but required further development to bridge independent service systems, build and sustain meaningful family and youth involvement, to better support local SOCs, and to address ongoing challenges. Local SOCs utilized county specific reports in discussions and to develop goals and activities. Monitoring change invited discussions regarding the effectiveness of strategies and activities, and changes in structure, technical assistance strategies, increased cross-system collaboration, new funding for school based mental health services, and sustained funding for family involvement through support of local SOCs.

\section{Exploratory Longitudinal Study}

In the spirit of monitoring implementation progress, the readiness survey was repeated twice during the expansion grant. Patterns of mean ratings at the local and state level remained similar to a national study of previously CMHI funded local grants. ${ }^{3}$ Using the SOCIS translational framework, for the state SOC, for Provider Accountability and Performance Measurement System, initial adequate ratings dropped in 2016; for General System Performance, adequate initial and 2016 ratings dropped in 2019. Although still within a mid-level range of SOC implementation overall, mean factor ratings for 2014 were typically higher compared to subsequent years. Stakeholders asked if observed changes were significant.

A MANOVA explored the use of a more rigorous statistical approach to identify significant change during funding cycles. With the MANOVA, statistically significant 
differences in the level of implementation emerged between 2014 and 2016, and between 2014 and 2018 for specific factors. For outreach and access to care and skilled provider network, mean factor ratings were significantly lower over time. For individualized, comprehensive, and culturally competent treatment, the trend was different with improved ratings in 2016, which waned by 2018. Observed mean changes in family choice and voice and collaboration were not statistically significant. Unlike using the translational measurement strategy with specific counties and at the state-level, examining goals, activities and reported progress or a related qualitative case study, ${ }^{23}$ the exploratory analysis of aggregated county and state mean factor found no progress and significant negative change in a few factors. Disaggregating survey results to examine state level implementation was limited by the small number of respondents and incomplete surveys.

Change theories. Trans-theoretical stages of change theory, ${ }^{44}$ familiar to behavioral health practitioners, and Rogers ${ }^{45}$ similar stages of change framework for implementation of innovation within organizations provide a context to understand the process of SOC adoption and development ${ }^{46}$ Following the initial (beginning) perceived need and matching of SOC values and principles to the child mental health system, SOCIS mid-level implementation is comparable to two parts of Roger's implementation framework: redefining and/or restructuring and clarifying, which cover a wide range of implementation tasks. ${ }^{44}$ After a system decides to implement a SOC, during the redefining and/or restructuring phase, the innovation (SOC) is adapted to fit into the system and the system's infrastructure changes. During the clarifying phase, as more stakeholders are involved, the relationship between SOC and the system are more clearly defined and established. When the SOC values, principles, and framework become a routine part of the system's structure and activities, the SOC is sustained (High Level). This 
study of specific factor ratings found evidence of both redefining/restructuring and clarifying processes in state and local SOC development. Both existing and newly established SOCs sought clarification of their role and often redefined the purpose and structure of their collaboratives.

Through readiness assessment and reassessments, SOCIS factor definitions and questions provided clarification. For example, the SOCIS defined collaboration through factor definitions and specific questions to assess the extent to which an interagency team met to discuss system planning for children and services, frequency of participation from education, shared resources, staff training, formal agreements, purchasing of services, and service plan development. ${ }^{41}$ Interim survey results led to in-depth discussions and revision of strategic plan strategies, funding, and activities. In the last year of the grant, restructuring occurred with increased crosssystem attention to mental health within the Commission on the Status of Children, increased collaboration among the state's child service agencies, and transformation of the grant's governance board to an advisory child mental health committee. ${ }^{11}$

Strengths and limitations. The SOCIS provided a snapshot of the child mental health system's state and local development through key informants' ratings of SOC factors in one Midwestern state, reflecting the nature and level of SOC implementation at the state and local levels. From a practical standpoint, the translational method of interpreting SOCIS findings provided an easily understood framework for SOC stakeholders. The SOCIS worked well as a readiness assessment to inform strategic planning. The survey process and result sharing also raised awareness about and improved understanding of the SOC framework.

SOCIS limitations. Though the findings offer good insight into SOC development, they should be interpreted with caution. Reliability and validity of the instrument had been studied at the county, but not at the state level. Within and between counties, developers acknowledged 
SOCIS limitations. ${ }^{41}$ Variability within and between counties was limited to six of the 14 original factors when measured by intraclass correlation. Small local sample sizes and the heterogeneous nature of national respondents raised concerns about between county results. Did small local sample sizes affect reliability? It was unclear if observed within and between county differences were due to differences in implementation or to respondent's perspectives (knowledge). ${ }^{41}$ Similar concerns appeared in this study.

Sampling methodology and survey. This study's convenience sampling methodology contributed limitations. Consistent with the national study's methodology, this study recruited diverse respondents to assess county and state level SOC development. In the resulting convenience sample, participation varied from one to 29 respondents for specific counties. Respondent type across time periods also varied. For the readiness assessment, respondent types were MH (37.3\%) and CSO (30.6\%), ED (14.4\%), OCP (8.9\%), and YF (8.4\%). The mix changed in 2016: MH (30.8\%), OCS (26.9\%), ED (19.6\%), OCP (17.8\%) and YF (4.9\%). In 2018, respondents included MH (25.7\%), OCS (28.9\%), ED (17.4\%), OCP (22\%), and YF (6.1\%). For studies of this nature, stratified and targeted sampling approaches may be more fitting.

Both respondent type and size possibly influenced factor means. The use of inferential analysis to identify statistically significant change was further limited by inconsistent participation of county stakeholders and the relatively low number of state surveys. The solution, aggregating ratings for participating counties and the state to develop a global measure, may not have reflected the impact of the state level CMHI grant. The survey was relatively long, including concepts unfamiliar to many respondents. Not all respondents rated every SOCIS factor, limiting the inferential analysis to more frequently rated, perhaps more familiar factors. 
Time, alone, may not explain SOC development. ${ }^{45}$ Implementation research considers time, but recognizes the complexity of organizational or system decision-making due to the large number of involved people. ${ }^{44}$. Possible explanations for this study's results include the complexity of the implementation process, ${ }^{44,47}$ effectiveness of planned strategies, respondents' perspectives and knowledge and the study's methodology. Some planned SOC activities may not have worked or may not have been well implemented. Decreasing survey ratings for OAC and SPN may have reflected respondents' increased recognition of common service challenges across SOCs. ${ }^{3}$ Regarding expected change related to CMHI grants, observed changes in Collaboration and Governance factors paralleled clarification and restructuring implementation processes during the grants. ${ }^{44}$ In contrast to foundational studies related to the SOCIS, in this study, the survey was utilized during the grant funding cycle, not as a post grant study. ${ }^{3,9,41}$

\section{Implications for Behavioral Health}

The system of care framework provides a foundation to effectively address the emotional and behavioral health needs of children and youth by establishing and supporting conditions necessary for access to effective services and supports. ${ }^{4,5,8-12,14,19,32}$ Implementation requires endorsement of the core system of care values and principles through infrastructure, policies, and programs. ${ }^{4,}{ }^{46}$ Further, periodic evaluation of the child mental health system infrastructure, policy development, and outcomes provides information needed for quality improvement initiatives. ${ }^{43}$, 47

The use of SOC value-based instruments, such as the SOCIS, combined with qualitative information, can provide valuable information to focus and inform strategic planning, technical assistance, and to support conditions necessary for accessible, effective child behavioral health services. To sustain SOC implementation and development, the inherent complexities of the 
implementation process and of evaluation resources warrant additional research. Despite methodological challenges, the meaningful inclusion of multiple perspectives from youth and families, service systems, service organizations, education, other child service organizations, etc. is needed. Further development and refinement of easily understood, normed instruments to monitor and manage SOC development at both local and state levels is needed. ${ }^{48}$

\section{Conflict of Interest Statement}

The authors of this study have no conflicts of interest to report. 


\section{References}

1. Cook, JR., Kilmer, RP. Evaluating systems of care: Missing links in children's mental health research. Journal of Community Psychology. 2004; 32(6): 655-674.

2. Knitzer, J, Cooper, J. Beyond integration: Challenges for children's mental health. Health Affairs. 2006; 25(3): 670-679.

3. Kutash, K, Greenbaum, PE, Wang, W, et al. Levels of system of care implementation: A national benchmark study. The Journal of Behavioral Health Services \& Research. 2011; 38(3): 342-357.

4. Stroul, B, Friedman, R. A system of care for children and youth with severe emotional disturbances. Washington, DC: Georgetown University Child Development Center, National Technical Assistance Center for Children’s Mental Health, 1986.

5. Stroul, BA, Blau, GM, Friedman, RM. Updating the system of care concept and philosophy. Washington, DC: Georgetown University Center for Child and Human Development, National Technical Assistance Center for Children's Mental Health, 2010.

6. Knitzer, J. Unclaimed children: The failure of public responsibility to children and adolescents in need of mental health services. Washington, DC: Children's Defense Fund, 1982.

7. Friedman, RM. Children's mental health: A discussion and elaboration on Knitzer and Cooper's article. Data Trends. 2006; 137.

8. Pires, SA. Building systems of care: A primer. $2^{\text {nd }}$ ed. Washington DC: National Technical Assistance Center for Children's Mental Health, Georgetown University Child Development Center, 2010. 
9. Boothroyd, RA., Greenbaum, PE, Wang, W, et al. Development of a measure to assess the implementation of children's systems of care: The systems of care implementation survey (SOCIS). The Journal of Behavioral Health Services \& Research. 2011; 38(3): 288-302.

10. Callejas, LM, Hernandez, M, Nesman, T, et al. Creating a front porch in systems of care: Improving access to behavioral health services for diverse children and families. Evaluation and Program Planning. 2010; 33(1): 32-35.

11. Doyle, GF. Indiana system of care implementation project: Final programmatic progress report, October 1, 2014-September 29, 2018. Indianapolis, IN: Indiana Family and Social Service Administration, Division of Mental Health and Addiction, 2018.

12. Coldiron, JS, Bruns, EJ, Quick, H. A comprehensive review of wraparound care coordination research, 1986-2014. Journal of Child and Family Studies. 2017; 26(5): 1245-1265.

13. Effland, VS, Walton, BA, McIntyre, JS. Connecting the dots: Stages of implementation, wraparound fidelity and youth outcomes. Journal of Child and Family Studies. 2011; 20(6): 736-746.

14. Bickman, L, Noser, K, Summerfelt, WT. Long-term effects of a system of care on children and adolescents. The Journal of Behavioral Health Services \& Research. 1999; 26(2): 185-202.

15. Huang, L, Stroul, B, Friedman, R, et al. Transforming mental health care for children and their families. American Psychologist. 2005; 60(6): 615-627. 
16. National Research Council and Institute of Medicine. Preventing mental, emotional, and behavioral disorders among young people: Progress and possibilities. Washington, DC: The National Academies Press, 2009.

17. Pires, S, Gilmer, T, McLean, J, et al. Faces of Medicaid series: Examining children's behavioral health service use and expenditures, 2005-2011. Hamilton, NJ: Center for Health Care Strategies, 2018.

18. Bruns, EJ, Walker, JS, Zabel, M, et al. Intervening in the lives of youth with complex behavioral health challenges and their families: The role of the wraparound process. American Journal of Community Psychology. 2010; 46(3-4): 314-331.

19. Bruns, EJ, Walker, JS, Bernstein, A, et al. Family voice with informed choice: coordinating wraparound with research-based treatment for children and adolescents. Journal of Clinical Child \& Adolescent Psychology. 2014; 43(2): 256-269.

20. Knitzer, J. Children's mental health policy: Challenging the future. Journal of Emotional and Behavioral Disorders. 1993; 1(1): 8-16.

21. Weisz, JR, Sandler, IN, Durlak, JA, et al. Promoting and protecting youth mental health through evidence-based prevention and treatment. American Psychologist. 2005; 60(6): 628.

22. Winters, NC, Metz, WP. The wraparound approach in systems of care. Psychiatric Clinics of North America. 2009; 32(1): 135-151.

23. Anderson, JA. The need for interagency collaboration for children with emotional and behavioral disabilities and their families. Families in Society. 2000; 81(5): 484-493. 
24. Hernandez, M, Nesman, T, Mowery, D, et al. Cultural competence: A literature review and conceptual model for mental health services. Psychiatric Services. 2009; 60(8): 1046-1050.

25. Little, V. Transdisciplinary care: Opportunities and challenges for behavioral health providers. Journal of Healthcare for the Poor and Underserved. 2010; 21(4): 1103-1107.

26. Wells, R, Hillemeier, MM, Bai, Y, et al. Health service access across racial/ethnic groups of children in the child welfare system. Child Abuse \& Neglect. 2009; 33(5): 282-292.

27. Kooreman, H, Anderson, JA, Wright, E. The dawn project helps Indiana youth. Available online at https://archives.iupui.edu/bitstream/handle/2450/770/247_DAWN.pdf?sequence=1\&isAll owed=y. Accessed December 10, 2018.

28. Cooper, JL, Aratani, Y, Knitzer, J, et al. Unclaimed children revisited: The status of children's mental health policy in the United States, Report. New York, NY: National Center for Children in Poverty, Mailman School of Public Health, Columbia University, 2008.

29. Patton, MQ. Getting to maybe: Evaluation, systems thinking, and complexity science. Plenary presentation at the $21^{\text {st }}$ Annual Research Conference, A System of Care for Children's Mental Health, Expanding the Research Base, Tampa, FL, 2008.

30. Behar, LB, Hydaker, WM. An analysis of readiness in system of care communities. A report to the Child, Adolescent and Family Branch, Center for Mental health Services, Substance Abuse and Mental Health Services Administration, U.S. Department of Health and Human Services, 2012. 
31. Rosenblatt, A, Woodbridge, MW. Deconstructing research on systems of care for youth with EBD. Journal of Emotional and Behavioral Disorders. 2003; 11(1): 27-37.

32. Holden, W, Santiago, R. Findings on the implementation of systems of care at nine CMHS grant communities. System-of-Care Evaluation Brief. 2003; 5(2): 1-4.

33. Walker, JS, Koroloff, N, Schutte, K. Implementing high quality collaborative individualized service/support planning: Necessary conditions. Portland, OR: Portland State University, Research and Training Center on Family Support and Children's Mental Health, 2003.

34. Substance Abuse and Mental Health Services Administration. Justification of estimates for appropriations committees. Fiscal year 2016. Department of Health and Human Services, 2016. Available at https://www.samhsa.gov/sites/default/files/samhsa-fy2016congressional-justification_2.pdf. Accessed on November 25, 2019.

35. Substance Abuse and Mental Health Services Administration. The comprehensive community mental health services for children with serious emotional disturbances program: Report to Congress 2016. U.S. Department of Health and Human Services. Center for Mental Health Services, 2016. Available at https://store.samhsa.gov/system/files/pep18-cmhi2016.pdf. Accessed on November 25, 2019.

36. Anderson, JA, Ergulec, F, Ruschman, NL. Indiana system of care: A case study of development, implementation, and evolution. Report prepared for the Indiana's System of Care. Bloomington, IN: Families, Communities, and Schools (FoCuS), 2016. 
37. Anderson, JA, Ergulec, F, Ruschman, NL. Indiana system of care phase II: A case study of development, implementation, and evolution. Indiana University, Bloomington, IN: Families, Communities, and Schools (FoCuS), 2018.

38. Lyons, JS. Communimetrics: A communication theory of measurement in human service settings. Springer, New York, 2009.

39. Urdapilleta, O, Kim, G, Wang, Y, et al. National evaluation of the Medicaid demonstration waiver home- and community-Based alternatives to psychiatric residential treatment facilities: Final evaluation report. Columbia, MD: IMPAQ International, 2013. Available at http://www.medicaid.gov/Medicaid-CHIP-Program-Information/ByTopics/Delivery-Systems/Downloads/CBA-Evaluation-Final.pdf. Accessed on November 25, 2019.

40. Greenbaum, P, Friedman, RM, Kutash, K, et al. Systems of care implementation survey (SOCIS, version.2.3.4). Tampa, FL: Research \& Training Center for Children's Mental Health Louis de la Parte, Florida Mental Health Institute College of Behavioral \& Community Sciences, University of South Florida, 2008.

41. Greenbaum, PE, Wang, W, Boothroyd, RA, et al. Multilevel confirmatory factor analysis of the System of Care Implementation Survey (SOCIS). Journal of Behavioral Health Services \& Research. 2011; 38(3), 303-326.

42. Tabachnick, BG, Fidell, LS. Using multivariate statistics. 6th Ed. New York: Pearson, 2001.

43. Brannan, AM, Brashears, F, Gyamfi, P, et al. Implementation and development of federally-funded systems of care over time. American Journal of Community Psychology. 2012; 49(3-4), 467-482. 
44. Prochaska, JO, DiClemente, CC. Stages and processes of self-change of smoking: Toward an integrative model of change. Journal of Consulting and Clinical Psychology. 1983; 51(3): 390-395.

45. Rogers, EM. Diffusion of innovation. $5^{\text {th }}$ Ed. New York, NY: Free Press, 2003.

46. Effland, VS, Walton, BA, McIntyre, J. Using change theories to assess systems of care development. In: C Newman, C Liberton, K Kutash et al. (Eds). The $17^{\text {th }}$ annual research conference proceedings: A system of care for children's mental health: Expanding the research base. Tampa, FL: The Research and Training Center for Children's Mental Health, University of South Florida, 2005, pp. 15-18.

47. Hernandez M, Armstrong M, Green AL, et al. National survey of state children's mental health directors: Current status and future directions. The Journal of Behavioral Health Services \& Research. 2017; 44(1), 3-24.

48. Rosas, SR, Behar, LB, Hydaker, WM. Community readiness within systems of care: The validity and reliability of the system of care readiness and implementation measurement scale (SOC-RIMS). The Journal of Behavioral Health Services \& Research. 2016; 43(1): 18-37. 